\title{
Biopolímeros: Aplicaciones de andamios en medicina regenerativa
}

\author{
Biopolymers: Scaffold Applications in Regenerative Medicine \\ Juan Sebastián Guerra Villacis. ${ }^{1}$, Seqqat Rachid. ${ }^{2}$, Christian Patricio Narváez Muño. ${ }^{3}$ \\ \& Marbel Torres Arias. ${ }^{4}$
}

Recibido: 04-05-2021 / Revisado: 15-05-2021 /Aceptado: 01-06-2021/ Publicado: 05-07-2021

DOI: https://doi.org/10.33262/anatomiadigital.v4i3.1754

\begin{abstract}
Biopolymers have become an indispensable tool for the development of regenerative medicine, their broad spectrum has allowed the emergence of new techniques for the generation of scaffolds of various sizes, shapes, with unique structural characteristics capable of generating and innovating new treatments before catastrophic diseases, its application by all branches of research such as neurology, endocrinology, in the cardiovascular area, for tissue repair or
\end{abstract}

\section{Resumen}

Los biopolímeros se han convertido en un herramienta indispensable para el desarrollo de la medicina regenerativa, su amplio espectro ha permitido la aparición de nuevas técnicas para la generación de andamios de diversos tamaños, formas, con características estructurales únicas capaces de generar e innovar tratamientos nuevos ante enfermedades catastróficas, su aplicación por todas las ramas de investigación como la neurología, endocrinología, en el área cardiovascular,

\footnotetext{
${ }^{1}$ Departamento de Ciencias de la Vida y Agricultura, Carrera de Ingeniería en Biotecnología, Universidad de las Fuerzas Armadas ESPE, Sangolqui, Ecuador, jsguerra@espe.edu.ec, https://orcid.org/0000-00032527-7308

${ }^{2}$ Universidad de las Fuerzas Armadas ESPE. Departamento de Ciencias de la Vida y la Agricultura. CENCINAT.rseqqat@espe.edu.ec

3 Departamento de Ciencias de la Energía Mecánica, Universidad de las Fuerzas Armadas, ESPE, Sangolqui, Ecuador cpnarvaez1 @espe.edu.ec. https://orcid.org/0000-0002-3472-4037

4 Departamento de Ciencias de la Vida y Agricultura, Laboratorio de Inmunología y Virología, CENCINAT, GISAH, Universidad de las Fuerzas Armadas, ESPE, Sangolqui, Ecuador, rseqqat@espe.edu.ec, $\quad$ https://orcid.org/0000-0002-8362-3689; mmtorres@espe.edu.ec. https://orcid.org/0000-0002-3902-5083
} 
organ donation has produced its application as drug conductors or transporters to achieve a guided release increasing the effectiveness and reducing adverse effects in the case of cancer treatments. The objective of this review is to know the fundamentals of regenerative medicine, the advances produced from the use of biopolymers as a tool capable of developing functional biomaterials, types, synthesis mode and applicability in treatments. This research was carried out from the compilation of scientific articles related to the area of public health and the application of functional scaffolds as therapy. The functionalization of scaffolds lies in the use of biocompatible polymers capable of binding to a substrate in a controlled environment for the development of a cellular matrix, generating the production of a specific tissue according to the target cells that have been investigated, thanks to this the possible rejection of a graft produced with the same cells of the patient allows the appearance of structures such as blood vessels or biocompatible organs. This work recapitulates the importance of the use of biopolymers in medicine, production techniques, their structure, form and most important applications for the treatment against diseases.

Keywords: Scaffolds, regenerative medicine, biomaterials, tissue engineering para la reparación de tejidos o donación de órganos ha producido su aplicación como conductores o transportadores de fármacos para lograr una liberación guiada aumentando la efectividad y disminuyendo efectos adversos en el caso de tratamientos contra el cáncer. El objetivo de esta revisión es conocer los fundamentos de la medicina regenerativa, los avances producidos a partir del uso de biopolímeros como una herramienta capaz de desarrollar biomateriales funcionales, tipos, modo de síntesis y aplicabilidad en tratamientos. Esta investigación se realizó a partir de la recopilación de artículos científicos relacionados al área de la salud pública y la aplicación de andamios funcionales como terapia. $\mathrm{La}$ funcionalización de andamios radica en la utilización de polímeros biocompatibles capaces de unirse a un sustrato en un ambiente controlado para el desarrollo de una matriz celular, generando la producción de un tejido en específico acorde a las células diana que se han investigado, gracias a esto el posible rechazo ante un injerto producido con las mismas células del paciente permite la aparición de estructuras como vasos sanguíneos u órganos biocompatibles. Este trabajo recapitula la importancia del uso de biopolímeros en la medicina, las técnicas de producción, su estructura, forma y aplicaciones más importantes para el tratamiento contra enfermedades.

Palabras claves: Andamios, medicina regenerativa, biomateriales, ingeniería de tejidos

\section{Introducción}

Con el pasar de los años la medicina clínica avanza muy rápidamente con logros sustanciales, la esperanza de vida estimada de los seres humanos ha aumentado 
considerablemente. Aunque estos avances de la tecnología son dignos de mención, traen consigo obstáculos asociados, a los que hay que hacer frente a medida que los cuerpos envejecen, lo que plantea nuevos retos como el envejecimiento, disfunción de tejidos y órganos; en la actualidad la mayor cantidad de tratamientos consiste en la implementación de un trasplante de órgano, el cuál no siempre se encuentra disponible. La escasez de tejidos y órganos podría solucionarse mediante la reconstrucción y el desarrollo de tejidos sintéticos en los que un andamio natural o desarrollado sintéticamente está totalmente celularizado con las propias células del paciente, eliminando así la necesidad de tejidos/órganos de donantes (Guo \& Ma, 2018). El uso de sistemas mecánicos no cumplen en su totalidad con la función normal del órgano o tejido generando un declive en la calidad de vida de los pacientes y requieren una inversión muy alta para ser tratados (Orive, Hernández, Garcón, Igartúa, \& Pedráz, 2003; Serrato, Nieto, \& Aguilera, 2015).

Existe ahora un reto de buscar nuevos métodos, herramientas y materiales para generar tejidos sintéticos que permitan mejorar nuestro bienestar. Muchos autores señalan que reconstruir un órgano completo, denso (corazón, riñón, etc.) o hueco (tráquea), es un reto de una complejidad inimaginable (Jayasinghe, 2017).

El desarrollo de la medicina moderna busca cumplir dicho reto mediante la irrupción en una nueva área que relaciona una ciencia innovadora como la nanotecnología para la producción de técnicas, productos y tratamientos capaces de ayudar a la humanidad contra enfermedades o problemas relacionados al área de la salud degenerativa (Mazaheri, Eslahi, Ordikhaln, Tamjid, \& Simchi, 2015). La medicina regenerativa a lo largo de los años ha sufrido procesos diferenciados de acuerdo a nuevos materiales descubiertos y su funcionalidad; en un principio se emplearon biomateriales inertes para ser empleados como una estructura sustituta en ciertas partes del cuerpo como una prótesis (Bai, Gao, \& Syed, 2018). Luego se desarrolló una matriz o andamio biológico que mediante su estructura permite promover un ambiente apropiado para el crecimiento y proliferación in situ de las células; y por último la aparición de una nueva rama la nanomedicina que a nivel de nanoescala recrea la funcionalización de las moléculas en el organismo, optimizando su tiempo de aparición y reacción (Bai, Gao, \& Syed, 2018). El descubrimiento de nuevos materiales conocidos como nanomateriales o biomateriales cuya función es recrear o formar tejidos funcionales a partir del control celular gracias a su capacidad de organizarse, crecer, diferenciarse y formar una matriz funcional bajo condiciones controladas (Bai, Gao, \& Syed, 2018). Estas condiciones se combinan en un complejo proceso orgánico que requiere señales endocrinas, hormonales, químicas, de diferenciación, de posición o interacciones entre las células y la matriz para mediante fuerzas mecánicas se logre la formación de una estructura en 3 dimensiones completamente funcional (Gamiz, et al., 2021; Morales, 2014).

Los nanomateriales pueden incluirse en la formación de cualquier tipo de tejido, puede ir desde reconstrucciones de piel, cartílagos, huesos y órganos creados a partir de andamios y células los cuales han permitido un paso importante en la ingeniería de tejidos (Cruz, Severo,, \& Azzolin, 2017). Según, Goldenberg, Lancheta \& Dekker (2020), lamentablemente existen ciertas restricciones y legislaciones las cuales colocan una gran 
cantidad de limitaciones en este tipo de tecnologías para ser tratadas en humanos, pero la utilización de modelos animales han permitido una gran cantidad de avances con resultados favorables muy cercanos a la realidad, brindando nuevas posibles soluciones para aumentar la efectividad de un tratamiento ante alguna enfermedad en específico o hacia lesiones graves sufridas por algún individuo. (Mazaheri, Eslahi, Ordikhaln, Tamjid, \& Simchi, 2015).

El objetivo de esta revisión es conocer los fundamentos de la medicina regenerativa, los avances producidos a partir del uso de biopolímeros como una herramienta capaz de desarrollar biomateriales funcionales, tipos, el modo de síntesis y aplicabilidad en tratamientos para brindar una visión de su funcionalidad.

\section{Medicina regenerativa}

La aparición de enfermedades catastróficas de origen genético, infeccioso, lesiones o daños permanentes en órganos y tejidos por accidentes de gran magnitud, fallas a nivel cardiovascular o problemas de conexión neuronal pueden producir la alteración de las células de un tejido generando una posible destrucción o disminución del rendimiento de un órgano, mermando la calidad de vida de una persona lo que ha dado paso al desarrollo de la medicina regenerativa (Karabasz, Bzowska, \& Szczepanowicz, 2020). Los principales obstáculos de la medicina moderna se basan en el restablecimiento y regeneración de la función normal de un órgano o tejido; los cuales pueden ser cubiertos mediante tres técnicas específicas; terapia celular, ingeniería tisular y la regeneración tisular (Rosa, 2013; Morrison, 2014; Ochoa, Nieto \& Aguilera, 2015).

Terapia celular: consiste en la utilización de células nuevas que ingresan al cuerpo como agente terapéutico, involucra gran cantidad de células que pueden ser de carácter regenerativo, reparativo, protectora o inmunoreguladora dentro de las cuales están las células madre, estas se pueden obtener de tejidos como la médula ósea, el cordón umbilical y la pulpa dental. Mediante la implantación de este nuevo material celular sobre un tejido dañado pueden lograr su recuperación (Serrato, Nieto, \& Aguilera, 2015). Las células pueden ser obtenidas ex vivo mediante un cultivo autogénico es decir de las células del mismo paciente o xenogénico si proviene de otro (Dong et al., 2020). Su principal aportación se ha visto en el trasplante de médula ósea o transfusiones sanguíneas con la finalidad de reconstruir el tejido hematopoyético y el sistema inmune; ayudando a combatir enfermedades relacionadas con osteoporosis, aumentando la densidad ósea total, calcio sérico, espacio medular y disminuyendo el riesgo de fracturas (Ejeian et al.,2020). La obtención de células madre derivadas de médula ósea como tratamiento han permitido el desarrollo de tratamientos en contra de varios tipos de enfermedades cardiovasculares, isquemia crónica, alteraciones oculares, trastornos neurológicos, miopatías, diabetes y enfermedades hepáticas (Hernández, 2006).

Ingeniería tisular: tiene como objetivo principal la construcción de tejidos in-vitro a partir de células de la misma persona para sustituir, reparar o incrementar las actividades funcionales de los propios tejidos orgánicos (Tortorella et,al., 2020). Según indica 
Morales (2014) su fundamento consiste en cultivar células en una matriz tridimensional conocida como andamio enriquecidos con factores de crecimiento que faciliten su desarrollo hacia un tejido funcional para trasplantarlo hacia un órgano receptor (Bai, Gao, $\&$ Syed, 2018). La ingeniería tisular presenta una gran cantidad de ventajas asociadas al sistema de trasplante de órganos por la presencia de agentes infecciosos o virus ya que al cultivarse células del mismo paciente la posibilidad de un rechazo inmune es muy baja y la necesidad de medicamentos inmunosupresores no es muy alta por lo que no se presentarán efectos secundarios como anemias o neuropatías secundarias (Tabla 1). (Xie et al., 2020).

Regeneración Tisular: consiste en el desarrollo del tejido in situ, se promueve el crecimiento celular sobre el propio tejido dañado mediante el uso de biomateriales, factores de crecimiento y control específico en la liberación de fármacos para que exista un desarrollo adecuado del tejido (Liu et al.,2020). La mayor cantidad de avances producidos mediante esta técnica se da en la salud oral que busca eliminar enfermedades periodontales mediante la restauración de hueso y ligamento dental con la ayuda de un injerto óseo (Martinez, 2009).

\section{Nanomateriales en Medicina}

La aplicación de nanomateriales en el desarrollo de estructuras biológicas permite encontrar una armonía entre los componentes materiales y celulares enfocados en un tratamiento específico con un beneficio terapéutico (Yang, et al., 2020). Para que se produzca el crecimiento celular normal en un individuo debe existir una relación directa mediante señales biomoleculares entre células y su matriz extracelular, esta liberación de componentes solubles favorecen la adhesión celular permitiendo su multiplicación y futura formación de tejidos (Bose, et al., 2020). Los biomateriales empleados en suplir esta matriz extracelular deben ser capaces de generar estas señales de liberación de moléculas para estimular la diferenciación y proliferación celular. La matriz generada funcionará como un sustrato o microcápsula para el crecimiento celular ya sea en la superficie o en su interior, pueden ser materiales naturales como el colágeno, fibrina, fibroína o de carácter sintético como el polietilenglicol, ácido poliláctico, policaprolactona (Alonzo, AnilKumar, Roman, Tasnim, \& Joddar, 2019). Su funcionamiento recae en la similitud a la matriz extracelular cubriendo todas las condiciones necesarias para el correcto crecimiento de las células, por lo tanto los andamios son funcionalizados con componentes bioactivos como hormonas, citoquinas, factores de transcripción o factores de crecimiento que desencadenan en una liberación controlada de moléculas que facilitan su resistencia y elasticidad moldeándose en un tamaño y forma capaz de adaptarse al paciente activándose bajo ciertos requisitos como el pH, la temperatura o un estímulo mecánico en específico para liberar los factores de crecimiento o fármacos que facilitarán la regeneración del tejido (Zheng, et al., 2021). 
Tabla 1. Organoides desarrollados con Ingeniería Tisular en 2D y 3D

\begin{tabular}{|c|c|c|c|c|c|}
\hline Órganoides & Células & $\begin{array}{l}\text { Método } \\
\text { de } \\
\text { Siembra }\end{array}$ & In-vivo & In-vitro & Referencias \\
\hline $\begin{array}{l}\text { Corazón } \\
\text { (producción de } \\
\text { tejido, venas y } \\
\text { arterias 3D ) }\end{array}$ & $\begin{array}{l}\text { Células } \\
\text { endoteliales } \\
\text { aórticas de } \\
\text { rata y células } \\
\text { cardíacas } \\
\text { neonatales } \\
\text { de rata. } \\
\text { HUVECs, } \\
\text { progenitores } \\
\text { cardíacos } \\
\text { humanos, } \\
\text { hMSC o } \\
\text { cardiomicocit } \\
\text { os }\end{array}$ & $\begin{array}{l}\text { Inyección, } \\
\text { perfusión } \\
\text { en la aorta } \\
\text { y en la } \\
\text { arteria } \\
\text { braquiocef } \\
\text { álica, aorta } \\
\text { pregrado }\end{array}$ & $\begin{array}{l}\text { Dinámico } \\
\text { (7-30d) } \\
\text { Estático } \\
(21 d)\end{array}$ & $\begin{array}{l}\text { Heterotópi } \\
\text { co }(7 d)\end{array}$ & $\begin{array}{l}\text { (Sánchez } \\
\text { et al., 2015; } \\
\text { Weymann } \\
\text { et al., 2014) }\end{array}$ \\
\hline $\begin{array}{c}\text { Pulmón } \\
\text { (organoide } \\
\text { primitivo/parcialm } \\
\text { ente completo) }\end{array}$ & $\begin{array}{l}\text { Células } \\
\text { epiteliales y } \\
\text { endoteliales } \\
\text { pulmonares } \\
\text { humanas } \\
\text { Población } \\
\text { pulmonar } \\
\text { neonatal de } \\
\text { rata y células } \\
\text { endoteliales } \\
\text { microvascula } \\
\text { res de rata } \\
\text { Células } \\
\text { endoteliales } \\
\text { derivadas de } \\
\text { HUVEC y } \\
\text { hMSC o } \\
\text { iPSC y } \\
\text { células } \\
\text { perivasculare } \\
\text { S }\end{array}$ & $\begin{array}{l}\text { Perfusión } \\
\text { en la } \\
\text { arteria, } \\
\text { vena, } \\
\text { bronquios } \\
\text { y haz } \\
\text { pulmonar }\end{array}$ & $\begin{array}{l}\text { Dinamico } \\
(4-21 d) \\
\text { Estático } \\
(28 d)\end{array}$ & $\begin{array}{l}\text { Ortópico } \\
\text { en ratas } \\
\text { por } 3 \mathrm{~h} \\
\text { Ortópico } \\
\text { en cerdos } \\
\text { por } 1 \mathrm{~h}\end{array}$ & $\begin{array}{l}\text { (Doi et al., } \\
\text { 2017; Gilpin } \\
\text { \& Yang, } \\
\text { 2017; Zhou } \\
\text { et al., 2018) }\end{array}$ \\
\hline $\begin{array}{c}\text { Riñón } \\
\text { (organoide } \\
\text { primitivo completo } \\
\text { / tamaño pequeño } \\
\text { 3D) }\end{array}$ & $\begin{array}{l}\text { HUVECS y } \\
\text { células } \\
\text { renales } \\
\text { neonatales } \\
\text { de rata }\end{array}$ & $\begin{array}{l}\text { Perfusión } \\
\text { en la } \\
\text { arteria } \\
\text { renal } \\
\text { Perfusión } \\
\text { asistida } \\
\text { por vacío }\end{array}$ & $\begin{array}{l}\text { Dinámico } \\
(5,7 \mathrm{~d}) \\
\text { Estático } \\
(16 \mathrm{~h}, 5 \mathrm{~d}, 30 \\
\text { d) }\end{array}$ & $\begin{array}{l}\text { Ortópico } \\
\text { en ratas } \\
\text { Subcutáne } \\
\text { o en } \\
\text { ratones } \\
\text { SCID }\end{array}$ & $\begin{array}{l}\text { (Bombelli } \\
\text { et al., 2018; } \\
\text { Du et al., } \\
2016 \text { ) }\end{array}$ \\
\hline
\end{tabular}


Vol. 4, $\mathrm{N}^{\circ}$ 3, p. 6-33, julio-septiembre, 2021

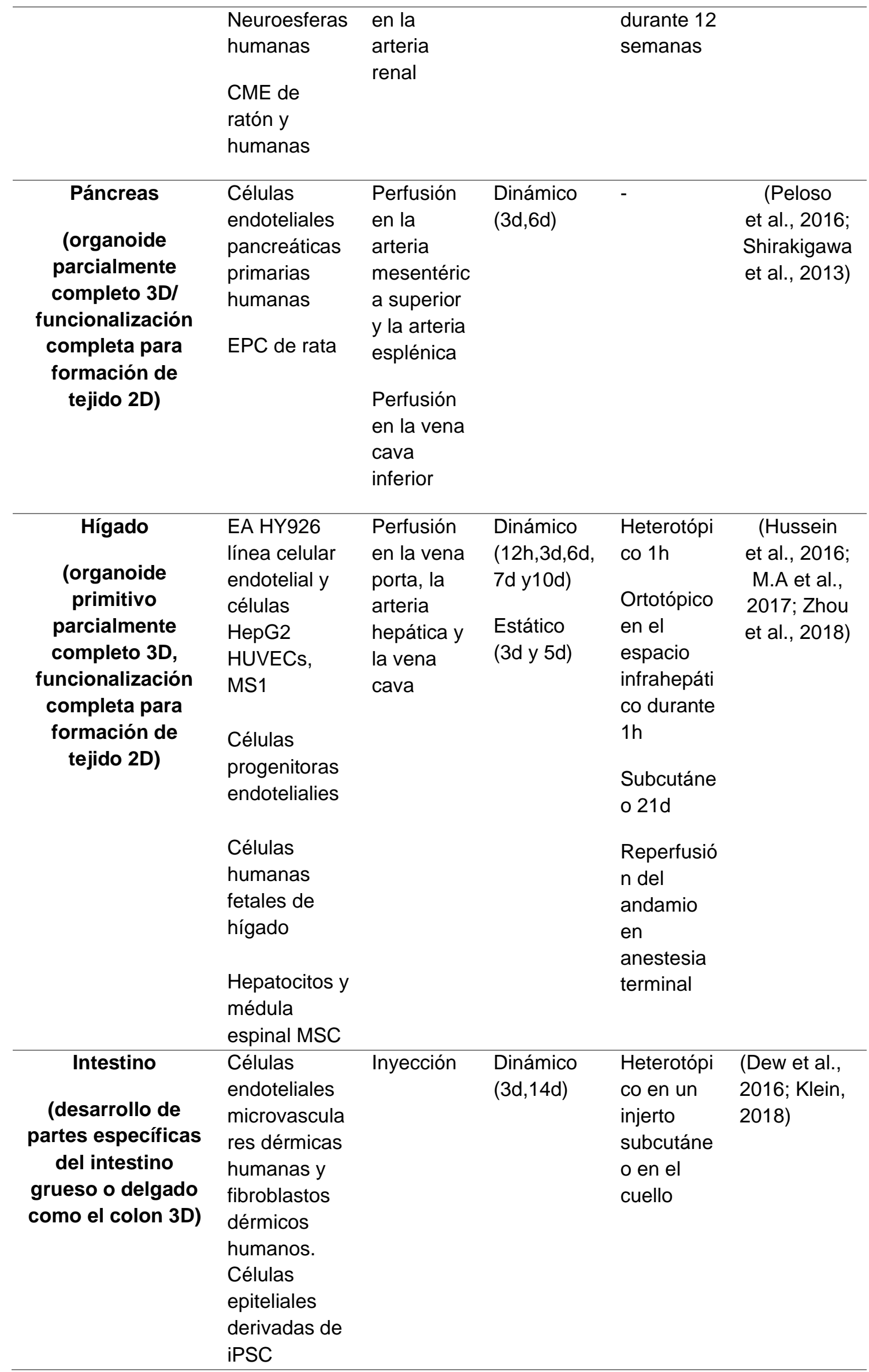


Tabla 1. Se presenta los diferentes tipos de organoides que se han podido desarrollar mediante la ingeniería tisular en 2 o 3 dimensiones, enfocándose en el tipo de células utilizadas, el método de siembra y si se los ha realizado in-vitro o in-vivo.

Fuente: Elaboración propia

Para lograr la administración controlada de señales bioquímicas o físicas mediante la utilización de un biomaterial se deben considerar la actividad y estabilidad biológica de las sustancias bioactivas, la cantidad de carga del andamio, la distribución de las biomoléculas en el andamio y la afinidad cinética de liberación de las moléculas, estos sistemas pueden ser implementados al momento de la creación del andamio o añadirlos por separado al momento de generar la matriz; lo que se busca es orientar la función celular para la liberación de moléculas específicas que permitan la adhesión y proliferación celular hacia la formación de un tejido en específico (Wang, et al., 2020).

\section{Andamios}

Se han descubierto una gran cantidad de materiales capaces de brindar una superficie usada como matriz extracelular los cuales se pueden diferenciar por su naturaleza biológica o sintética, por su composición, forma, tamaño, resistencia y elasticidad; pero deben ser diseñados para suplir 3 funciones esenciales la adhesión, diferenciación y proliferación celular mediante la conducción e inducción de sustancias bioactivas (Tabla 2 y 3) (Zare, et al., 2021). El estudio de biomateriales es la base para el desarrollo de la medicina regenerativa buscando la forma más adecuada de cada componente ya que puede afectar directamente la respuesta biológica (Alam, Jo, Park \& Cho, 2020).

Tabla 2. Ventajas y desventajas de los Biomateriales sintéticos.

\begin{tabular}{|c|c|c|c|}
\hline Biomaterial & Ventajas & Desventajas & Referencias \\
\hline $\begin{array}{c}\text { Biocerámicas } \\
\text { Hidroxiapatita (HA) } \\
\text { Vidrio bioactivo } \\
\text { Fosfato tricálcico ( } \beta \text { - } \\
\text { TCP) }\end{array}$ & $\begin{array}{l}\text { Alta resistencia del } \\
\text { material } \\
\text { Biocompatibilidad } \\
\text { Resistencia a la } \\
\text { corrosión } \\
\text { Componentes } \\
\text { inorgánicos similares } \\
\text { Osteoconductividad } \\
\text { Hidrofilia }\end{array}$ & $\begin{array}{l}\text { Difícil de moldear } \\
\text { Módulo elástico } \\
\text { excesivo }\end{array}$ & $\begin{array}{l}\text { (Sha, et al., } \\
2021 \text {; Zeng, et } \\
\text { al., 2017). }\end{array}$ \\
\hline $\begin{array}{c}\text { Polímeros } \\
\text { Policaprolactona } \\
\text { (PCL) } \\
\text { Polietilenglicol (PEG) } \\
\text { Poliácido láctico } \\
\text { (PLA) } \\
\text { Poliácido glicólico } \\
\text { (PGA) }\end{array}$ & $\begin{array}{l}\text { Biodegradable } \\
\text { Biocompatible } \\
\text { Fácilmente moldeable y } \\
\text { disponible } \\
\text { Resistencia mecánica } \\
\text { adecuada }\end{array}$ & $\begin{array}{l}\text { Lixiviable en los } \\
\text { fluidos corporales } \\
\text { Difícil de esterilizar } \\
\text { Hidrofóbico (PCL) } \\
\text { Mala respuesta } \\
\text { celular } \\
\text { Subproductos ácidos }\end{array}$ & $\begin{array}{l}\text { (Gao, et al., } \\
2021 ; \text { Lin, et } \\
\text { al., 2021; } \\
\text { Moin, et al., } \\
\text { 2020). }\end{array}$ \\
\hline $\begin{array}{l}\text { Compuestos } \\
\text { Polietileno con } \\
\text { incrustaciones de } \\
\text { fibras de carbono } \\
\text { Cemento óseo }\end{array}$ & $\begin{array}{l}\text { Excelentes propiedades } \\
\text { mecánicas } \\
\text { Resistente a la corrosión }\end{array}$ & $\begin{array}{l}\text { Caro } \\
\text { Métodos de } \\
\text { fabricación laboriosos }\end{array}$ & $\begin{array}{l}\text { (Wang, et al., } \\
\text { 2021; Deng, } \\
\text { et al., 2021). }\end{array}$ \\
\hline
\end{tabular}


Tabla 2. Se presenta las ventajas y desventajas para el desarrollo de andamios a partir de la utilización de biomateriales de origen sintético.

Fuente: Elaboración Propia

Tabla 3. Ventajas y desventajas de los Biomateriales naturales.

\begin{tabular}{|c|c|c|c|}
\hline Biomaterial & Ventajas & Desventajas & Referencias \\
\hline Quitosano & $\begin{array}{l}\text { Biológicamente renovable } \\
\text { Biodegradable } \\
\text { Biocompatible } \\
\text { No antigénico } \\
\text { No tóxico } \\
\text { Biofuncional } \\
\text { Materiales bioadhesivos }\end{array}$ & $\begin{array}{l}\text { Inestabilidad en } \\
\text { medios ácidos }\end{array}$ & $\begin{array}{l}\text { (Loutfy, et al., } \\
\text { 2021; Kittana, et } \\
\text { al., 2021; Afzali, } \\
\text { et al., 2021). }\end{array}$ \\
\hline Fibrina & $\begin{array}{l}\text { Induce una mejor interacción } \\
\text { celular } \\
\text { Alta biocompatibilidad }\end{array}$ & $\begin{array}{l}\text { Rápida degradación } \\
\text { in-vivo } \\
\text { Dificultad para } \\
\text { mantener la integridad } \\
\text { estructural }\end{array}$ & $\begin{array}{l}\text { (Xie, et al., } \\
2020 ; \\
\text { Lichtenstein, et } \\
\text { al., 2021) }\end{array}$ \\
\hline $\begin{array}{l}\text { Fibroína de } \\
\text { seda }\end{array}$ & $\begin{array}{l}\text { Biocampatividad } \\
\text { Degradabilidad lenta } \\
\text { Excelentes propiedades } \\
\text { mecánicas }\end{array}$ & $\begin{array}{l}\text { La producción de seda } \\
\text { de araña es muy } \\
\text { reducida }\end{array}$ & $\begin{array}{l}\text { (Hou, et al., } \\
\text { 2020; Liu, Zhu \& } \\
\text { Tang, 2020). }\end{array}$ \\
\hline Colágeno & $\begin{array}{l}\text { Biodegradabilidad } \\
\text { Biocompatibilidad en medio } \\
\text { fisiológico } \\
\text { Baja antigenicidad } \\
\text { Biocompatible } \\
\text { Buen reconocimiento celular }\end{array}$ & $\begin{array}{l}\text { Propiedades } \\
\text { mecánicas deficientes }\end{array}$ & $\begin{array}{l}\text { (Talaat, et al., } \\
\text { 2020; Luo, et al; } \\
\text { 2021). }\end{array}$ \\
\hline $\begin{array}{c}\text { Ácido } \\
\text { hialurónico y } \\
\text { alginato }\end{array}$ & $\begin{array}{l}\text { Biocompatible } \\
\text { Fácilmente acoplable } \\
\text { Buen reconocimiento celular } \\
\text { Métodos de gelificación } \\
\text { sencillos }\end{array}$ & $\begin{array}{l}\text { Propiedades } \\
\text { mecánicas deficientes }\end{array}$ & $\begin{array}{l}\text { (Ma, et al., } \\
\text { 2021; Xuan, et } \\
\text { al; 2021). }\end{array}$ \\
\hline
\end{tabular}

Tabla 3: Se presentan las ventajas y las desventajas del desarrollo de andamios a partir de la utilización de biomateriales de origen natural.

Fuente: Elaboración Propia.

Morales (2014), menciona que el diseño de un biomaterial debe cumplir ciertas especificaciones como su biocompatibilidad ya que no debe generar rechazo por parte del sistema inmune del huésped, su conductividad relacionada a la capacidad de fijación y proliferación celular, su afinidad por incorporar factores inductivos encargados de dirigir y mejorar el crecimiento tisular, la eficiencia en el crecimiento vascular para el transporte de biomoléculas y su oxigenación, su resistencia mecánica y un procesamiento sencillo para que pueda ser replicable y aplicable para un tratamiento en específico (Bai, Gao, \& Syed, 2018). La superficie de un andamio, su composición y estructura es un parámetro fundamental al momento de su síntesis pues las señales celulares generadas dependen de estas características ligando directamente el destino celular por la liberación de señales bioquímicas (Dong \& Ma, 2019). El principal problema identificado para la síntesis de 
un biomaterial recae en su manipulación ya que puede existir una alta tasa de

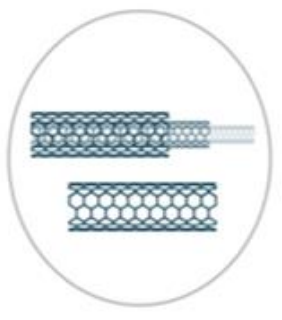

Nanotubos

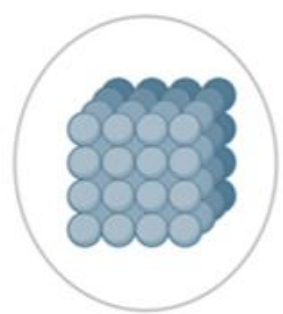

Nanocristales

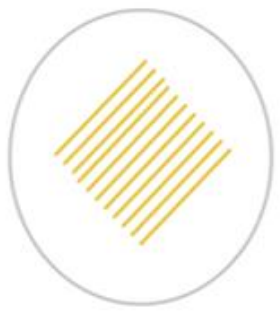

Nanocables

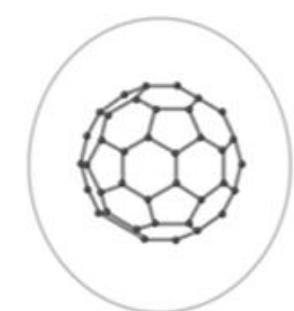

Nanocápsulas

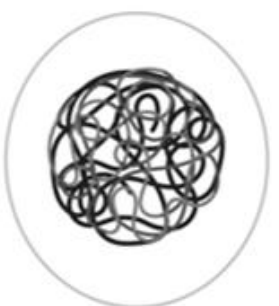

Nanopartículas

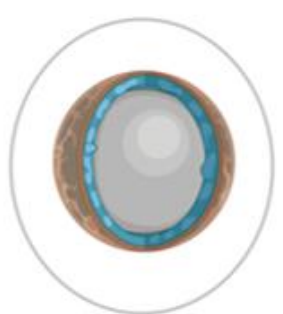

Nanoesferas

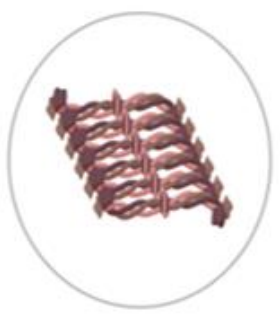

Nanofibras

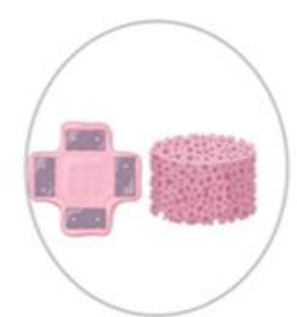

Geles/Andamios

porosos

contaminación, su determinación estructural idónea lleva una gran cantidad de ensayos de prueba y error a nivel de laboratorio; por último, el proceso de implementación celular puede ser muy largo y complejo (Rabiee, et al., 2020; Chen, et al., 2020).

Los polímeros son los biomateriales más utilizados para la generación de andamios gracias a su biocompatibilidad, su biodegradabilidad, su resistencia mecánica, su porosidad ligada al correcto transporte de biomoléculas y nutrientes permitiendo una amplia variación de procesamientos capaces de cumplir con la proliferación celular, pueden existir de dos tipos naturales y sintéticos en diversas formas nanotubos, nanocables, esferas, en forma de gel o en películas fibrosas que buscan guiar la diferenciación celular de la manera más idónea dependiendo del tipo celular y tejido que desea regenerar (Figura 1) (Guo \& Ma, 2018).

\section{Tipos de Andamios}

Andamios de Nanotubos: consisten en andamios tubulares de escala nanométrica, sintetizados principalmente de carbono, silicio o grafeno sus características físicas varían dependiendo del grado de enrollamiento en una pared simple o múltiple pared en donde se enrolla dentro de sí mismo generando un área superficial mayor, su diámetro pueden ampliarse de acuerdo al método de síntesis y puede ser empleado como un conductor o transmisor de señal fluorescentes para la detección de proteínas gracias a sus propiedades ópticas únicas que emiten un espectro infrarrojo, permitiendo la detección molecular de proteínas ligadas a la producción de enfermedades cancerígenas o como tratamiento a desórdenes degenerativos (Hendler-Neumark \& Bisker, 2019; Dong \& Ma, 2019).

Andamios de Nanocables: son estructuras generadas a partir de carbono o silicio, se producen sobre una matriz capaz de actuar como un conductor de señales eléctricas, se pueden conjugar con múltiples agentes multifuncionales generando una mayor 
proporción de superficie funcionando como un vehículo terapéutico para la liberación de fármacos gracias a sus cargas (Vidu, et al., 2014; Chen, et al., 2019).

Andamios esféricos: son estructuras esféricas de tamaño uniforme con un diámetro a 1000 nm que proporcionan una alta estabilidad física, homogéneos por su forma pueden ser utilizadas como vehículo para la deposición de proteínas específicas o fármacos que ayudan en el funcionamiento celular (Karabasz, Bzowska, \& Szczepanowicz, 2020). Consiste de 2 partes el núcleo y la cáscara en donde el fármaco puede ligarse a la parte central o unirse en la superficie para una deposición guiada en las células diana objetivo; el núcleo puede ser de carácter sólido, líquido o gaseoso dependiendo de su aplicabilidad, mientras que la cubierta es desarrollada mediante polímeros; gracias a su estructura se puede colocar uno o varios fármacos dependiendo de la cantidad de compartimentos generados en el núcleo y su cubierta puede ser permeable o semipermeable siendo el grosor y porosidad los encargados de la velocidad de liberación del fármaco (Dong, et al., 2020).

Andamios de Geles: son redes tridimensionales a escala nanométrica formadas por el entrecruzamiento de polímeros sintetizados de manera química o física, su principal función está relacionada a la administración controlada de fármacos; reaccionan a estímulos programados como $\mathrm{pH}$, temperatura, luz o reacciones de óxido reducción; dando una liberación direccionada para el funcionamiento correcto de las células objetivo y permitir un estímulo para un crecimiento acelerado (Hajebi, et al., 2019; Cao, et al., 2020).

Andamios de Fibras o fibrinas: consiste en una estructura polimérica a nivel nanométrica electrohilada mediante fuerzas electrostáticas que entrega una superficie porosa y estable capaz de funcionar como matriz extracelular, su composición puede ser de carácter sintético o biológico y su mayor aplicación está ligado a la reconstrucción guiada de tejido óseo permitiendo la liberación guiada de proteínas específicas para la proliferación y diferenciación celular (Boda, et al., 2019; Ghasemian-Lemraski, et al., 2021).

Gracias a las propiedades biodegradables de los materiales y el control durante su síntesis existe el modelamiento de formas tridimensionales, la estimulación mecánica y física de factores biológicos capaces de regenerar tejidos, proporcionar ambientes de acogida y generar fuerzas de atracción para la deposición guiada de fármacos (Tabla 4) (GungorOzkerim, Inci, Zhang, Khademhosseini, \& Dokmeci, 2018).

Tabla 4. Aplicaciones Biomédicas con el uso de varios tipos de andamios.

\begin{tabular}{cllll}
\hline $\begin{array}{c}\text { Tipos de } \\
\text { andamios }\end{array}$ & \multicolumn{1}{c}{ Aplicación } & \multicolumn{1}{c}{ In-vitro } & Animales o Humanos & Referencias \\
& & & & \\
\hline Nanotubos & $\begin{array}{l}\text { Restructurar y } \\
\text { reconectar } \\
\text { neuronas } \\
\text { dañadas. }\end{array}$ & $\begin{array}{l}\text { Crecimiento } \\
\text { celular. }\end{array}$ & $\begin{array}{l}\text { Prácticas en modelos } \\
\text { animales de ratones } \\
\text { para conexión neuronal. }\end{array}$ & $\begin{array}{l}\text { (Alonzo, } \\
\text { AnilKumar, } \\
\text { Roman, }\end{array}$ \\
& & & $\begin{array}{l}\text { Tasnim \& } \\
\text { Humanos sistemas de } \\
\text { administración de }\end{array}$ & $\begin{array}{l}\text { Joddar, } \\
\end{array}$ \\
\hline
\end{tabular}


Sistemas de administración de fármacos.

Detección de metabolitos biológicos (Biosensor).

$\begin{array}{lll}\text { Producción de } & \text { fármacos en el } & \text { 2019; Bose, } \\ \text { tejido } & \text { tratamiento contra el } & \text { et al., 2020; } \\ \text { neuronal } & \text { cáncer } & \text { Chen, et al., } \\ & & \text { 2020) }\end{array}$

$\begin{array}{ll}\text { Nanocables } & \begin{array}{l}\text { Sistemas de } \\ \text { administración de } \\ \text { fármacos. }\end{array} \\ & \text { Reconocer firmas } \\ \text { genéticas de } & \text { diferentes } \\ \text { partículas y } \\ \text { transmitir la } \\ \text { información. }\end{array}$

Producción de Administración de

(Chen, et

tejido

fármacos, modelos

al., 2019;

neuronal, animales tratamientos

Guo \& Ma, identificación contra la degeneración 2018; Shen, de señal de neuronal (Alzhaimer). et al., 2019) fluorescencia para la Humanos Liberación liberación guiada de fármacos en guiada de fármacos, fluoróforos para células objetivos

\begin{tabular}{|c|c|c|c|c|}
\hline Esferas & $\begin{array}{l}\text { Sistemas de } \\
\text { administración de } \\
\text { fármacos } \\
\text { inyectables de } \\
\text { depósito } \\
\text { (Tratamiento de la } \\
\text { enfermedad de } \\
\text { Alzheimer). }\end{array}$ & $\begin{array}{l}\text { Producción de } \\
\text { tejido } \\
\text { neuronal. } \\
\text { Encapsulación } \\
\text { de fármacos, } \\
\text { baja toxicidad, } \\
\text { aumento de } \\
\text { efectividad de } \\
\text { liberación en } \\
\text { células } \\
\text { objetivo }\end{array}$ & $\begin{array}{l}\text { Administración guiada } \\
\text { de fármacos en } \\
\text { modelos animales }\end{array}$ & $\begin{array}{l}\text { Chen, et al., } \\
\text { 2020; Dong, } \\
\text { et al., 2020; } \\
\text { Rabiee, et } \\
\text { al., 2020; } \\
\text { Meniani } \\
\text { \&Elaissari, } \\
\text { 2020) }\end{array}$ \\
\hline Geles & $\begin{array}{l}\text { Matrices para la } \\
\text { regeneración de la } \\
\text { piel (apoyan la } \\
\text { proliferación de } \\
\text { queratinocitos y } \\
\text { fibroblastos } \\
\text { dérmicos } \\
\text { humanos), } \\
\text { sobretodo en } \\
\text { heridas profundas, } \\
\text { permitiendo el } \\
\text { restablecimiento } \\
\text { en cortos periodos } \\
\text { de tiempo. } \\
\text { Producción de } \\
\text { otros tejidos, como } \\
\text { vasos sanguíneos, }\end{array}$ & $\begin{array}{l}\text { Crecimiento } \\
\text { celular } \\
\text { acelerado, } \\
\text { producción de } \\
\text { tejido } \\
\text { epidérmico, } \\
\text { articular y } \\
\text { muscular. } \\
\text { Obtención de } \\
\text { estructuras } \\
\text { como } \\
\text { ligamentos, } \\
\text { conductos } \\
\text { (venas y } \\
\text { arterias) }\end{array}$ & $\begin{array}{l}\text { Modelos animales para } \\
\text { la cicatrización } \\
\text { acelerada, prueba } \\
\text { funcional de conductos } \\
\text { y ligamentos. } \\
\text { Humanos: terapia de } \\
\text { crecimiento articular, } \\
\text { regeneración de } \\
\text { cartílago, cicatrización } \\
\text { epidérmica y muscular. }\end{array}$ & $\begin{array}{l}\text { (Bai, Gao, } \\
\text { \& Syed, } \\
\text { 2018; Chen } \\
\text { \& Stephen- } \\
\text { Inbaraj, } \\
\text { 2019; } \\
\text { Gamiz-Arco, } \\
\text { et al., 2021; } \\
\text { Zhou, et al., } \\
\text { 2021) }\end{array}$ \\
\hline
\end{tabular}




\begin{tabular}{|c|c|c|c|c|}
\hline & $\begin{array}{l}\text { ligamentos y } \\
\text { bronquios. }\end{array}$ & & & \\
\hline & $\begin{array}{l}\text { Diferenciación y } \\
\text { propagación para } \\
\text { el crecimiento de } \\
\text { cilios en el TEC } \\
\text { (tejido epitelial } \\
\text { ciliado). }\end{array}$ & & & \\
\hline $\begin{array}{l}\text { Fibras o } \\
\text { Fibrinas }\end{array}$ & $\begin{array}{l}\text { Apoyar la } \\
\text { adhesión de las } \\
\text { células madre, la } \\
\text { proliferación y } \\
\text { diferenciación in- } \\
\text { vitro. } \\
\text { La reparación de } \\
\text { una amplia gama } \\
\text { de tejidos in-vivo } \\
\text { como cartílagos } \\
\text { artificiales, } \\
\text { fragmentos de } \\
\text { tejido óseo, vasos } \\
\text { sanguíneos, tejido } \\
\text { epitelial y tejido } \\
\text { nervioso óseo. } \\
\text { Unión dermo- } \\
\text { epidérmica y la } \\
\text { reconstrucción de } \\
\text { la reepitelización } \\
\text { del espesor de la } \\
\text { piel. }\end{array}$ & $\begin{array}{l}\text { Crecimiento } \\
\text { celular } \\
\text { acelerado, } \\
\text { formación de } \\
\text { tejido } \\
\text { epidérmico, } \\
\text { óseo, } \\
\text { muscular y } \\
\text { articular. }\end{array}$ & $\begin{array}{l}\text { Modelos animales en } \\
\text { ratones para reparación } \\
\text { de tejido muscular y } \\
\text { epidérmico. } \\
\text { Humanos: tratamiento } \\
\text { para recuperación de } \\
\text { fracturas óseas, } \\
\text { recuperación acelerada } \\
\text { para cicatrización. }\end{array}$ & $\begin{array}{l}\text { (Boda, et } \\
\text { al., 2019; } \\
\text { Darwesh, } \\
\text { El-Dahhan, } \\
\text { \& Meshali, } \\
\text { 2020; Liu, et } \\
\text { al., 2020; } \\
\text { Zheng, et } \\
\text { al., 2021) }\end{array}$ \\
\hline
\end{tabular}

Tabla 4. Aplicación de andamios en el desarrollo de la medicina regenerativa para la obtención de estructuras celulares in-vitro, o in-vivo en animales o pruebas realizadas en humanos para tratamiento médico.

Fuente: Elaboración propia

\section{Construcción de andamios}

De acuerdo al tipo de biomaterial empleado en la síntesis de un andamio se pueden generar una gran cantidad de procedimientos capaces de hallar su correcto funcionamiento cubriendo todos los requerimientos básicos para su utilización, dependiendo de sus características químicas, físicas y biológicas, dirigiéndolo a suplir el funcionamiento de la matriz extracelular proporcionando una mejor compatibilidad mecánica y un acoplamiento estructural entre las células y tejidos (TaŞli, et al., 2020). La metodología empleada en la construcción de un andamio va directamente relacionada a la estructura, forma y funcionalidad que se desee, por lo que si el andamio requerido tendrá una forma de esfera existen 3 métodos de síntesis; capa por capa, nanoprecipitación y nanoemulsión (Arai, et al., 2018). Si es de carácter tubular como nanotubos o nanocables los métodos empleados son nanoprecipitación o nanoemulsión para el 
desarrollo de geles se emplea una emulsión o mezcla polimérica, mientras que para el desarrollo de fibras se emplea la técnica de electrohilado (Cheng, et al., 2020).

Método capa por capa: consiste en desarrollar películas delgadas compuestos por multicapas mediante la técnica de adsorción secuencial por cargas. Zhou, Yang, Wang \& Cheng (2021) mencionan que sus inicios recaen en 1960 mediante el incrustamiento de micropartículas sobre diversos tipos de sustratos capaces de generar una corriente eléctrica gracias a las proteínas o moléculas orgánicas producidas sobre los sustratos, su mayor impulso recae en el estudio de polielectrolitos en 1990 por parte de Sukhoukovr. Gracias a su fácil segregación y procedimiento permite una multifincionalidad al modificar un polielectrolito mediante la agregación de polímeros, nanopartículas orgánicas o incluso nanotubos de carbono (Karabasz, Bzowska, \& Szczepanowicz, 2020). Su avance durante los últimos años ha permitido la creación de sistemas de administración de fármacos multifuncionales por sus condiciones, en donde se puede desarrollar una incorporación de la proteína objetivo a un direccionamiento de anticuerpos presentes sobre la célula objetivo manteniendo un ambiente controlado, otra aplicación recae en el uso de nanopartículas magnéticas que interactúan sobre un campo magnético externo generado por un nanoportador productor de cargas eléctricas, este tipo de atracción ha permitido la investigación celular en la reparación de tejidos, administración de fármacos, imágenes de resonancia magnética (Liu, et al., 2021; Gomha, et al., 2021).

Nanoprecipitación: Parte del principio de disolución de un nanoportador que es un andamio capaz de llevar un fármaco o una molécula orgánica a una célula diana (Karabasz, Bzowska, \& Szczepanowicz, 2020). Para su construcción existen fases orgánicas y acuosas que al añadir una sustancia activadora, como un polímero genera un desplazamiento del disolvente, se realiza por el método gota a gota o diálisis (Tao, Chow, $\&$ Zheng, 2019). El proceso inicia al unir la parte orgánica con la parte acuosa, al difundir el polímero sobre el solvente orgánico y precipitar por la fase no solvente genera la formación de un nanoportador. El resultado obtenido puede ser modificable cambiando la concentración del polímero, la relación de volumen y el método de inyección (Lammari, Louaer, Meniai, \& Elaissari, 2020).

Nanoemulsión: consiste en la emulsión de una fase orgánica con una fase acuosa mediante el uso de un agente estabilizante que reduce la tensión superficial entre las dos fases inmiscibles generando una estabilidad (Chen \& Stephen-Inbaraj, 2019). Para su formación se pueden aplicar métodos de alta y baja energía dependiendo de la aplicabilidad del resultado y el tamaño requerido que puede variar entre 10 a $600 \mathrm{~nm}$ (Karabasz, Bzowska, \& Szczepanowicz, 2020). El resultado puede ser aplicado en la síntesis de nanoportadores monoméricos o poliméricos dependiendo de los polímeros naturales o sintéticos empleados ampliando su rango de aplicabilidad. Se han descrito cuatro métodos para la síntesis por nanoemulsión que son: emulsificación coacervación, emulsificación múltiple, emulsificación-evaporación y emulsificación-difusión que se aplicarán dependiendo del tipo de andamio que se requiera generar (Kumar, Bishnoi, Shukla, \& Jain, 2019). 
Electrohilado: esta técnica fue desarrollada en el año de 1934 por el físico Anton Formhals caracterizada por la capacidad de formación de filamentos poliméricos a partir del uso de fuerzas electrostáticas capaces de definir características específicas como la flexibilidad, la alta porosidad, la relación entre el área y el volumen obtenida; el rendimiento mecánico; permitiendo la combinación de varios polímeros para la formación de una sola fibra específica (Wong, Chan, \& Chrzanowski, 2014). El equipo diseñado por Formhals se basa en 4 partes esenciales la fuente de poder con una capacidad de voltaje alta, el plato colector en el cual se irán formando las fibras, el capilar por donde saldrá el polímero y la bomba inyectora capaz de controlar la cantidad de sustancia que irá siendo hilada; este principio puede ser llevado a una gran cantidad de áreas dependiendo del tipo de polímero, el tamaño de la membrana y la resistencia que se busca adquirir; por lo que se puede utilizar en la formación de andamios para ingeniería de tejidos, apósitos o vendajes (Rockwood, Prenda, \& Kaplan, 2011). Para la formación de fibras poliméricas se debe tener una solución polimérica colocada dentro de una jeringa convencional la cual se conectará a la bomba inyectora hasta ser expulsada a través del capilar (Yao.C, Li, \& Song, 2009). Dicho capilar se encuentra conectado a una de las terminales de la fuente del alto voltaje que generará un campo eléctrico crítico necesario para vencer a las fuerzas intermoleculares de la solución las cuales afectarán directamente en el proceso de formación del jet estabilizándose mediante fuerzas electrostáticas de repulsión de los elementos dentro de la solución polimérica rompiendo la tensión superficial, generando una pequeña fibra muy delgada a nivel micro y nanométrica la cual irá siendo depositada en el plato colector que se encuentra conectada a la otra terminal de la fuente de poder (Weska, Vieira, \& Nogueira, 2009). La fibra generada es utilizada para la regeneración de tejidos que, de acuerdo a sus características poliméricas, tipo de síntesis y propiedades biológicas permitirá su aplicación en la cicatrización de heridas y agente antimicrobiano (Figura 2) (Ghasemian-Leranski., et al., 2021).

\section{Elaboración de un andamio polimérico por electrohilado para crecimiento de células epiteliales}




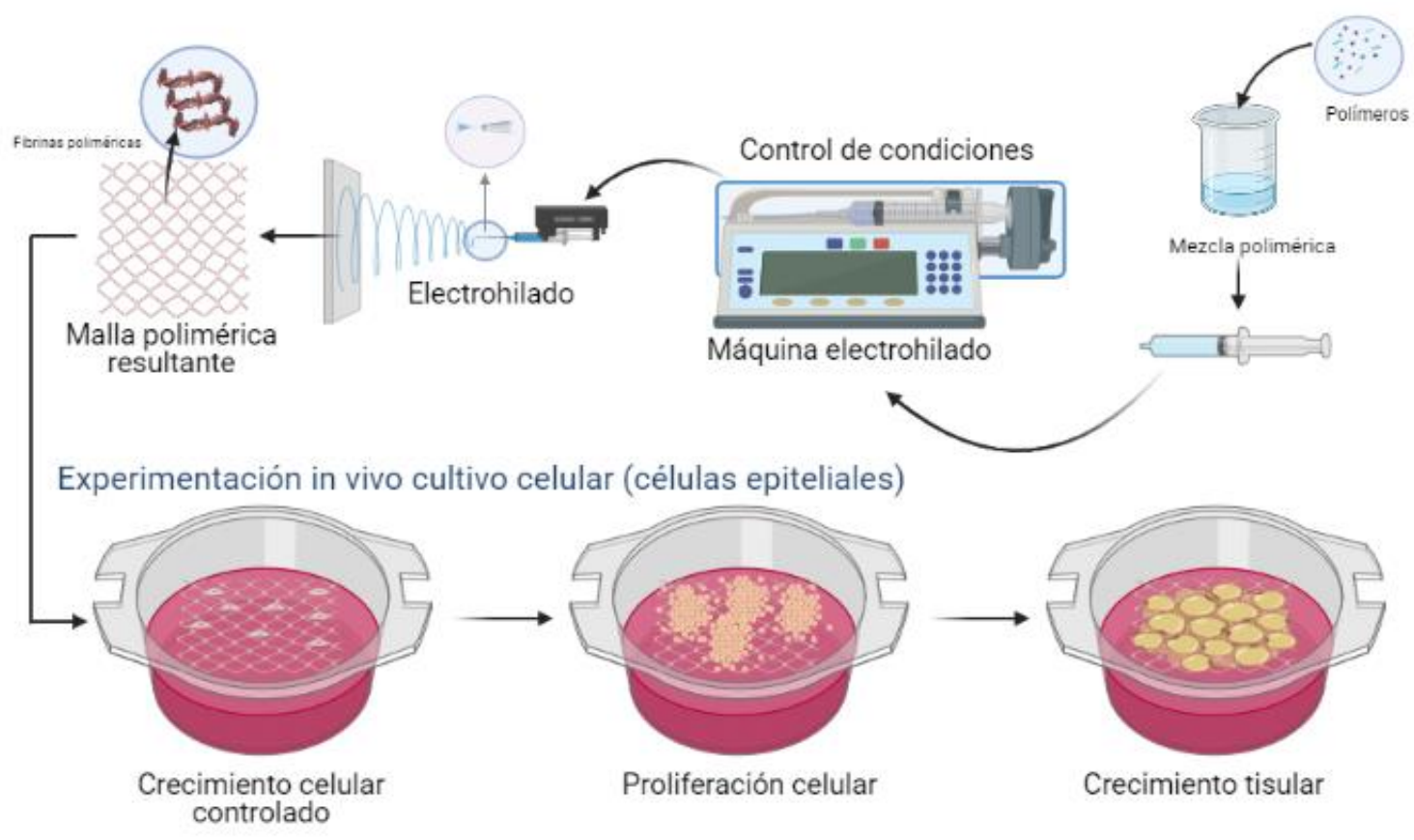

Figura 2. Elaboración de una malla polimérica a partir de la técnica de electrohilado para su experimentación en cultivo celular para la obtención de tejido epitelial.

Fuente: Elaboración propia Www.biorender.com

Impresión 3D: implica la formación de una película en 3 dimensiones mediante la superposición de células con andamios biológicamente compatibles y factores biológicos de activación para la regeneración biológica permitiendo la construcción de tejido formado de forma autónoma y con integridad estructural, su principal aportación se encuentra ligada al desarrollo de una matriz de cartílago articular debido su baja reparación gracias a la falta de vasos sanguíneos, este desarrollo permite generar tratamientos ligados a la administración de fármacos, la realización de autoinjertos para articulaciones y terapias funcionales (Cheng, et al., 2020; Arai, et al., 2018).

\section{Aplicaciones de Andamios en Medicina Regenerativa}

La medicina regenerativa es el umbral para la aplicación de andamios construidos a partir de biomateriales naturales y sintéticos en diversas formas y tamaños, gracias a la gran cantidad de aplicaciones que se les puede dar, su utilización se ha convertido en la base de muchos tratamientos y su efectividad cada día va en aumento (Figura 3) (Goldenberg, et al., 2020).

\section{Liberación Controlada de Fármacos}




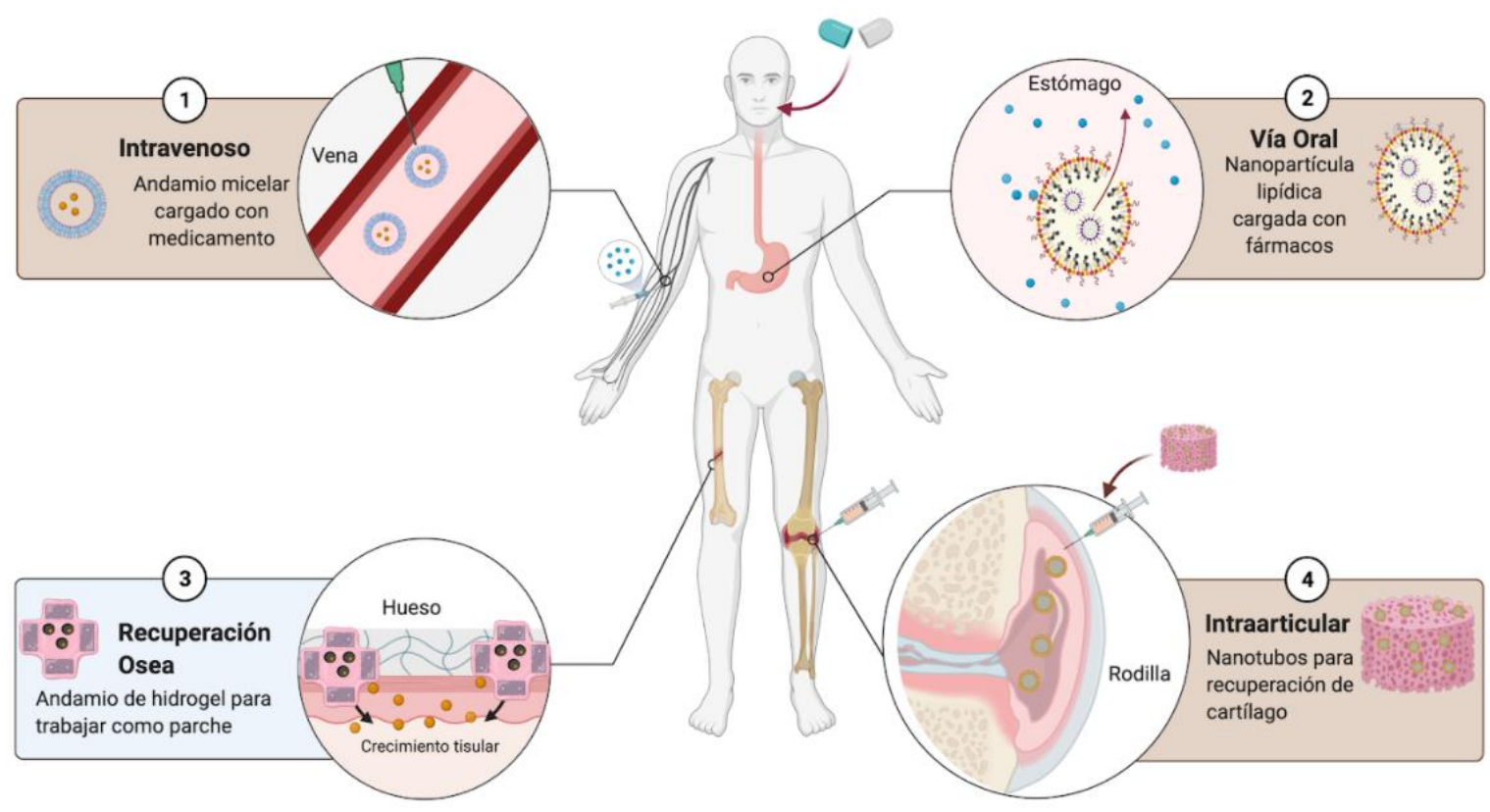

Figura 3. Métodos empleados para la liberación guiada de fármacos. 1 Método intravenoso, se inyecta directamente el andamio cargado con el medicamento en la vena para que sea dirigido por el sistema circulatorio al lugar requerido dentro del organismo. 2 Vía oral, ingresa el andamio en forma de nanopartícula lipídica al organismo para ser absorbida en el estómago y distribuirse al organismo. 3 Recuperación ósea, se coloca un andamio en forma de gel formado por fibrinas sobre la zona afectada con fractura o fisura y trabaja como parche para la regeneración y crecimiento tisular. 4. Vía intraarticular, se coloca un andamio en forma de nanotubo directamente sobre una articulación para que ayude a la regeneración del cartílago.

Fuente: Elaboración propia Www.biorender.com

El desarrollo de apósitos para la recuperación de heridas superficiales a nivel de epidermis se ha vuelto una respuesta para evitar enfermedades crónicas o prevenir condiciones físicas adversas, la utilización de hidrogeles se presenta como una solución gracias a sus características regenerativas promocionando un ambiente propicio para el crecimiento celular. Ghasemian-Lemraski, et al (2020) explica que al desarrollar hidrogeles poliméricos mediante la técnica de electrohilado impregnados de nanoparticulas de $\mathrm{Cu}$ como agente antimicrobiano para la recuperación de heridas crónicas en personas con problemas de cicatrización debido a la diabetes presenta resultados favorables disminuyendo el tiempo de curación en las primeras etapas gracias al desarrollo de tejido celular y evitando el crecimiento bacteriano.

Las bioimpresoras capaces de generar un andamio en tres dimensiones unificando todas sus propiedades bioactivas capaces de funcionalizar tejidos de manera acelerada permitiendo el desarrollo celular (Sha, et al., 2021). Uno de los campos más estudiados es la regeneración ósea por la cantidad de defectos óseos que siguen apareciendo debido a enfermedades catastróficas; el injerto óseo es uno de los más utilizados por su biocompatibilidad para lesiones de reparación o fracturas. La aplicación del uso de las nanoarcillas como un nuevo tipo de andamio se ha convertido en un área capaz de aumentar la regeneración celular y la formación de tejidos. Wang, et al (2020) produce 
un nuevo andamio mediante una impresora $3 \mathrm{D}$ en forma de nanobarras de atapulgita que es un mineral arcilloso cargado de magnesio hidratado capaz de mejorar el intercambio iónico entre superficies, probándolo con líneas celulares óseas determinan un incremento acelerado del hueso a nivel in-vitro siguiendo un proceso similar a la osificación membranosa sin la formación de un cartílago intermedio, observándose el desarrollo de incluso vasos sanguíneos dentro de los poros del andamio, convirtiéndose en una nueva forma de regenerar tejido óseo de manera efectiva y rápida. La utilización de nanomateriales funcionalizados para trabajar como una matriz extracelular ha llevado al desarrollo de injertos óseos por la arquitectura porosa resultante Zhou, et al (2020) encontraron que la producción de un andamio mediante vidrio bioactivo mesoporoso a partir de poliuretano y polidopamina dotado con la submucosa del intestino delgado porcina actúa como una matriz extracelular capaz de receptar proteínas ideales para la regeneración ósea

Dentro del área cardiovascular la utilización de andamios naturales tiene estricta relación a la formación de tejidos arteriales o vasos sanguíneos capaces de tratar enfermedades cardiorrespiratorias mejorando la circulación sanguínea y recuperando arterias o venas dañadas (Alonzo, AnilKumar, Roman, Tasnim, \& Joddar, 2019). Yang, et al (2020) Desarrollaron un andamio vascular en forma de armazón a partir de fibrina y poliuretano mediante la técnica de electrohilado permitiendo la adhesión y proliferación de células estromales mesenquimales capaces de desarrollar tejido para la formación de vasos sanguíneos.

La utilización de medicamentos fotosensibles para la realización de pruebas de resonancia magnética o rayos x pueden implicar riesgos severos para la salud por su toxicidad al organismo, pero son los únicos capaces de detectar diagnósticos severos gracias a la interacción específica con un tipo de células dañadas (McCravy, Ingram, \& Que, 2021). Darkwesh, El-Dahhan \& Meshali (2020) aplican el desarrollo de andamios de transporte producidos como nanofibras capaces de llevar un agente como la gadodiamida utilizado para la revelación en resonancia magnética al ingresar de manera intravenosa puede dispersarse por todo el organismo generando una toxicidad debido a su disociación en gadolinio un metal muy pesado y tóxico similar al calcio que puede interactuar en los huesos y bloquear el canal de calcio inhibiendo ciertas transmisiones nerviosas; al utilizar un nanotransportador para producir la liberación del agente en zonas específicas del organismo que se activen gracias a las condiciones del medio como el pH y moléculas orgánicas disminuye el riesgo de toxicidad y ofrece una optimización en la revelación de imágenes por resonancia.

Los nanotubos de carbono se han vuelto uno de los andamios más estudiados en el área de la medicina regenerativa referente a la administración guiada de fármacos gracias a su biocompatibilidad celular, conductividad y características físicas como longitud, grado de agregación y funcionalidad superficial que permiten la captación celular (Zare, et al., 2021). Esta multifuncionalidad ha llevado al desarrollo de varios estudios referentes al uso específico de medicamentos aumentando su eficacia de liberación en el tratamiento de enfermedades específicas como el cáncer, un ejemplo es el docetaxel una de las drogas 
más comunes aplicada durante la quimioterapia para evitar el crecimiento de células enfermas, mediante la interacción del fármaco con nanotubos de carbono funcionalizados con quitosano Li, et al (2018) determinaron que el nivel de efectividad de liberación a comparación del fármaco puro fue del $68 \%$ a un pH de 5 en un modelo animal de ratones convirtiéndose en una posible solución para la interacción del fármaco únicamente con las células tumorales.

\section{Avances de la medicina regenerativa en el Ecuador}

Existe el Instituto Nacional de Donación y Trasplante de órganos, tejidos y células (INDOT) el cual se basa en la Ley Orgánica de Donación y Trasplante de Órganos, Tejidos y Células vigente desde el año 2011 para determinar la disponibilidad y posibilidad de un paciente en estado grave (caso 0) ingresando en la Lista de Espera Única dictaminada en el Artículo 8 y revisada mediante la Asignación de acuerdo a la prioridad, vulnerabilidad, la ética y el tipo de órganos, tejido o célula requerida mencionado en el Artículo 9, para recibir una donación (Ministerio de Salud Pública, 2011).

Los ciudadanos ecuatorianos se pueden convertir en donantes en caso de sufrir un accidente, a menos que hayan manifestado lo contrario al momento de solicitar su identificación en el Registro Civil marcándose en su cédula que no desean convertirse en donador, INDOT será el encargado de determinar la jurisprudencia y situación de donación tanto si es en vida o post mortem solicitando toda la información y la documentación que verifique el deseo de la persona por entregar sus órganos total o parcialmente según sean requeridos y notificando a sus familiares de la manera más cálida, humana y brindando toda la ayuda posible como se establecen en los artículos 11, 12, 14 y 18. Se establece la capacidad del tratamiento con células madre e ingeniería tisular en los artículos 52 y 53 bajo la autorización previa del ente gubernamental, enfocándose en el desarrollo de nuevos tratamientos capaces de ayudar a la salud pública (Ministerio de Salud Pública, 2011).

La disponibilidad de un órgano o tejido puede ser muy limitada, por lo que el tiempo de espera puede conllevar años y un estilo de vida muy difícil para pacientes que sufren disfunción en algún órgano, el trasplante incluye un proceso complicado de inmunosupresión y aceptación del tejido u órgano extraño en el paciente que puede conllevar riesgo de rechazo produciéndose una pérdida de un órgano sano y la debilidad emocional en un paciente (Bai, Gao, \& Syed, 2018). Por lo tanto en el país se han ido desarrollando estudios capaces de evaluar los avances de la medicina regenerativa en la utilización de la terapia celular como base para la obtención de células madre mediante la gelatina de Wharton del cordón umbilical que busca su crecimiento para el tratamiento de enfermedades como la leucemia que necesitan un trasplante de médula ósea y la posibilidad de obtención de un donante compatible es sumamente bajo en un $25 \%$ entre hermanos, en un $10 \%$ en padres y $1 \%$ con algún familiar (Costa, 2015). Gracias a estos estudios el INDOT ha implementado la creación de un Banco Público de Sangre de Cordón Umbilical para mantener este tipo de células y utilizarlas en el caso de requerirlo, cumpliendo lo establecido en el artículo 53 para la utilización y manipulación de células 
madre se deberá tener la autorización de la entidad competente, no exista fines de lucro, debe haber un consentimiento informado de la o el donante hacia el receptor, no pueden tratarse las células embrionarias o fetales y se debe seguir un reglamento específico que se evidencie mediante toda la documentación correspondiente llevada por el practicante de la técnica en cuestión (Ministerio de Salud Pública, 2011). La aplicación de nuevas técnicas de producción de andamios dopados con metabolitos obtenidos de plantas endémicas del Ecuador se convertido en una nueva área por explorar Allauca, Guerra \& Lara (2019) mencionan la utilización de andamios dopados con sangre de drago en forma de nanoesferas obtenidas mediante impresión 3D destinadas a la liberación guiada de fármacos para el crecimiento tisular, determinando que gracias a las características cicatrizantes de la sangre de drago por los taninos presentes en su composición puede emplearse como un futuro andamio capaz de producir un crecimiento tisular mucho más acelerado; de esta manera se siguen desarrollando investigaciones capaces de ampliar el espectro de la medicina en el Ecuador hallando nuevas tecnologías y aplicaciones que brinden una solución a problemas de salud pública.

La aplicación de la medicina regenerativa mediante la utilización de andamios presenta una serie de ventajas en contra de los métodos tradicionales gracias a su mayor capacidad de respuesta, un estudio más profundo de los resultados a esperar, la especificidad del tratamiento al tratarse de un cultivo de las mismas células del paciente, aumentando la capacidad de recepción y asegurando su funcionalidad por la biocompatibilidad de los mismos, las facultades de los andamios ya sean naturales o sintéticos permiten un continuo desarrollo de la ingeniería tisular pues permiten la aparición de nuevos métodos capaces de tratar problemáticas a la salud sumamente difíciles, siendo mucho menos invasivas y compatibles con el organismo (Chen \& Stephen-Inbaraj, 2019). La posibilidad de tratar el cáncer de una manera mucho más específica es un gran ejemplo de esta, la liberación guiada de fármacos seguirá siendo uno de sus mayores potenciales y su estudio delimitará la posibilidad de si en un futuro cercano se podrá obtener una cura potencial. A su vez el costo elevado de las investigaciones por los equipos, materiales, tiempo y legislaciones se vuelve un pequeño obstáculo que se debe superar, pero la tecnología se está desarrollando de una forma tan acelerada que te permite soñar en un futuro en donde la utilización de andamios y la medicina regenerativa se convierta en la solución ante aquellos problemas de salud más catastróficos que afectan a la humanidad (Guo \& Ma, 2018; Zare, et al., 2021).

\section{Conclusiones}

- El descubrimiento de biomateriales funcionalizados como andamios en la medicina regenerativa se ha convertido en una de las herramientas fundamentales para el tratamiento de enfermedades catastróficas que afectan a la salud mundial mediante la ingeniería tisular.

- El uso de andamios prefabricados es utilizar un sistema de polímeros que se inyecta directamente en el lugar del defecto y que se polimeriza in situ utilizando calor, polímeros termorreactivos, o luz (polímeros fotorreactivos). En la actualidad, se está llevando a cabo una gran cantidad de investigaciones sobre 
todos los aspectos de la ingeniería de tejidos/medicina regenerativa en todo el mundo. A medida que el campo avanza, uno de los principales retos es tratar de imitar con mayor precisión la sofisticación de los biopolímeros natural en sustitución de los materiales sintéticos. A medida que existan mas biomateriales y biorreactores avanzados, permitirá conocer los mecanismos de señalización celular necesarios para el desarrollo de los tejidos, y reducir el número de pacientes que esperan tejidos de donantes.

- El Ecuador es capaz de utilizar este tipo de tecnologías gracias a una entidad pública relacionada directamente con el trasplante de órganos, tejidos y células INDOT, mediante el cual se puede desarrollar nuevas investigaciones en la aplicación de la medicina regenerativa.

\section{Referencias Bibliográficas}

Afzali, E., Eslaminejad, T., Yazdi-Rouholamini, S., Shahrokhi-Farjah, M., \& Ansari, M. (2021). Cytotoxicity Effects of Curcumin Loaded on Chitosan Alginate Nanospheres on the KMBC-10 Spheroids Cell Line. Int J Nanomedicine., 16(1), 579-589.

Alam, K., Jo, Y., Park, C., \& Cho, H. (2020). Synthesis of Graphene Oxide Using Atmospheric Plasma for Prospective Biological Applications. Int $J$ Nanomedicine., 15(1), 5813-5824.

Allauca, L., Guerra, G., \& Lara, H. (2019). Allauca, L., Guerra, G., \& Lara, H. (2019). Preliminary study of coating 3D Printed Polymeric Gyroid structures using "Dragon"s blood' extract as a potential delivery system. IEEE Fourth Ecuador Technical Chapters Meeting (ETCM), 1(10), 1-6.

Alonzo, M., AnilKumar, S., Roman, B., Tasnim, N., \& Joddar, B. (2019). 3D Bioprinting of cardiac tissue and cardiac stem cell therapy. Transl Res, 11(1), 64-83.

Arai, K., Murata, D., Verissimo, A., Mukae, Y., Itoh, M., Nakamura, A., . . Nakayama, K. (2018). Fabrication of scaffold-free tubular cardiac constructs using a Bio-3D printer. PLoS One., 13(12), 23-40.

Bai, X., Gao, M., \& Syed, S. (2018). Bioactive hydrogels for bone regeneration. Bioactive Materials, 50-68.

Boda, S., Almoshari, Y., Wang, H., Wang, X., Reinhardt, R., Duan, B., . . Xie, J. (2019). Mineralized nanofiber segments coupled with calcium-binding BMP-2 peptides for alveolar bone regeneration. Acta Biomater, 1(85), 282-293.

Bose, R., Tharmalingam, N., Choi, Y., Madheswaran, T., Paulmurugan, R., McCarthy, J., . . . Park, H. (2020). Intracellular Pathogens with Nanohybrid-Facilitated Antibiotic Delivery. Int J Nanomedicine., 15(1), 8437-8449. 
Cao, Z., Li, W., Liu, R., Li, C., Song, Y., Liu, G., . . L Liu, Y. (2020). pH-Responsive Fluorescence Enhanced Nanogel for Targeted Delivery of AUR and CDDP Against Breast Cancer. Int J Nanomedicine, 15(1), 8369-8382.

Chen, B., \& Stephen-Inbaraj, B. (10 de Mayo de 2019). Nanoemulsion and Nanoliposome Based Strategies for Improving Anthocyanin Stability and Bioavailability. Nutrients., 11(5), 1052-1073.

Chen, H., Zhao, X., Xi, Z., Zhang, Y., Li, H., Li, Z., . . Wang, T. (2019). A new biosensor detection system to overcome the Debye screening effect: dialysis-silicon nanowire field effect transistor. Int J Nanomedicine, 14(1), 2985-2993.

Chen, Y., Guan, M., Ren, R., Gao, C., Cheng, H., Li, Y., . . Xiong, W. (2020). Improved Immunoregulation of Ultra-Low-Dose Silver Nanoparticle-Loaded TiO2 Nanotubes via M2 Macrophage Polarization by Regulating GLUT1 and Autophagy. Int J Nanomedicine, 15(1), 2011-2026.

Cheng, Z., Xigong, L., Weiyi, D., Jingen, H., Shuo, W., Xiangjin, L., \& Junsong, W. (2020). Potential use of 3D-printed graphene oxide scaffold for construction of the cartilage layer. J Nanobiotechnology., 18(1), 97-110.

Costa, D. (2015). Implementación de protocolos de aislamiento y cultivo de células madre mesenquimales de la gelatina de wharton del cordón umbilical como base para estudios de regeneración de tejidos. Guayaquil : DSpace ESPOL.

Cruz, I., S. A., \& Azzolin, V. (2017). Regenerative potential of the cartilaginous tissue in mesenchymal stem cells: update, limitations, and challenges. Brasileira de Ortopedia, 52-68.

Darwesh, A., El-Dahhan, M., \& Meshali, M. (2020). New Oral Coaxial Nanofibers for Gadodiamide-Prospective Intestinal Magnetic Resonance Imaging and Theranostic. Int J Nanomedicine, 15(1), 8933-8943.

Deng, L., Jiang, H., Lu, F., Wang, H., Pu, Y., Wu, C., . . Zhang, X. (2021). Size and PEG Length-Controlled PEGylated Monocrystalline Superparamagnetic Iron Oxide Nanocomposite for MRI Contrast Agent. Int J Nanomedicine., 16(1), 201211.

Dong, J., \& Ma, Q. (2019). Integration of inflammation, fibrosis, and cancer induced by carbon nanotubes. Nanotoxicology, 13(9), 1244-1274.

Dong, J., Wu, Y., Zhang, Y., Yu, M., \& Tian, W. (2020). Comparison of the Therapeutic Effect of Allogeneic and Xenogeneic Small Extracellular Vesicles in Soft Tissue Repair. Int J Nanomedicine, 6975-6991.

Dong, W., Luo, Y., Zhan, G., Zhang, H., Liang, Y., Zhuo, Y., . . Zhong, W. (2020). Carbon Nanospheres Exert Antitumor Effects Associated with Downregulation of 4E-BP1 Expression on Prostate Cancer. Int J Nanomedicine., 15(1), 5545-5559. 
Ejeian, F., Razmjou, A., Nasr-Esfahani, M., Mohammad, M., Karamali, F., EbrahimiWarkiani, M., ... Chen, V. (2020). ZIF-8 Modified Polypropylene Membrane: A Biomimetic Cell Culture Platform with a View to the Improvement of Guided Bone Regeneration. Int J Nanomedicine, 10029-10043.

Gamiz-Arco, G., Gutierrez-Rus, L., Risso, V., Ibarra-Molero, B., Hoshino, Y., Petrović, D., . . Sanchez-Ruiz, J. (2021). Heme-binding enables allosteric modulation in an ancient TIM-barrel glycosidase. Nat Commun, 12(1), 380-396.

Gao, C., Yu, S., Zhang, X., Dang, Y., Han, D., Liu, X., . . . Hui, M. (2021). Dual Functional Eudragit@ S100/L30D-55 and PLGA Colon-Targeted Nanoparticles of Iridoid Glycoside for Improved Treatment of Induced Ulcerative Colitis. Int J Nanomedicine, 16(1), 1405-1422.

Ghasemian Lemraski, E., Jahangirian, H., Dashti, M. K., Sharafinia, S., RafieeMoghaddam, R., \& Webster, T. (2021). Antimicrobial Double-Layer Wound Dressing Based on Chitosan/Polyvinyl Alcohol/Copper: In vitro and in vivo Assessment. Int J Nanomedicine, 1(16), 223-235.

Goldenberg, B., Lacheta, L., Dekker, T., Spratt, J., Nolte, P., \& Millett, P. (2020). Biologics to Improve Healing in Large and Massive Rotator Cuff Tears: A Critical Review. Orthop Res Rev, 151-160.

Gomha, S., Abdelhady, H., Hassain, D., Abdelmonsef, A., El-Naggar, M., Elaasser, M., \& Mahmoud, H. (2021). Thiazole-Based Thiosemicarbazones: Synthesis, Cytotoxicity Evaluation and Molecular Docking Study. Drug Des Devel Ther., 15(1), 659-677.

Gungor-Ozkerim, P., Inci, I., Zhang, Y., Khademhosseini, A., \& Dokmeci, M. (2018). Bioinks for 3D bioprinting: an overview. Biomater Sci., 6(5), 915-946.

Guo, B., \& Ma, P. (2018). Conducting Polymers for Tissue Engineering. Biomacromolecules, 19(6), 1764-1782.

Hajebi, S., Rabiee, N., Bagherzadeh, M., Ahmadi, S., Rabiee, M., Roghani-Mamaqani, H., . . Hamblin, M. (2019). Stimulus-responsive polymeric nanogels as smart drug delivery systems. Acta Biomater, 1(92), 1-18.

Hendler-Neumark, A., \& Bisker, G. (2019). Fluorescent Single-Walled Carbon Nanotubes for Protein Detection. Sensors. Basel, 19(24), 5403-5419.

Hernández, P. (2006). Medicina Regenerativa II. Aplicaciones, realidad y perspectivas de la terapia celular. Rev Cubana Hematol Inmunol Hermoter.

Hou J, Y. D. (2020). The Roles of Integrin $\alpha 5 \beta 1$ in Human Cancer. Onco Targets Ther. 2020, 13(1), 13329-13344.

Jayasinghe, S. (2017). Thoughts on Scaffolds. Adv Byosyst, 10(1), 255-281. 
Karabasz, A., Bzowska, M., \& Szczepanowicz, K. (2020). Biomedical Applications of Multifunctional Polymeric Nanocarriers: A Review of Current Literature. Int J Nanomedicine, 8673-8696.

Kittana, N., Assali, M., Zimmermann, W., Liaw, N., Santos, G., Rehman, A., \& Lutz, S. (2021). Modulating the Biomechanical Properties of Engineered Connective Tissues by Chitosan-Coated Multiwall Carbon Nanotubes. Int J Nanomedicine., 16(1), 989-1000.

Kumar, M., Bishnoi, R., Shukla, A., \& Jain, C. (24 de Septiembre de 2019). Techniques for Formulation of Nanoemulsion Drug Delivery System: A Review. Prev Nutr Food Sci., 24(3), 225-234.

Lammari, N., Louaer, O., Meniai, A., \& Elaissari, A. (7 de Mayo de 2020). Encapsulation of Essential Oils via Nanoprecipitation Process: Overview, Progress, Challenges and Prospects. Pharmaceutics., 12(5), 431-452.

Lichtenstein, T., Mammadov, K., Rau, K., Große-Hokamp, N., Do, T., Maintz, D., \& Chang, D. (2021). Long-Term Follow-Up and Clinical Relevance of Incidental Findings of Fibrin Sheath and Thrombosis on Computed Tomography Scans of Cancer Patients with Port Catheters. Ther Clin Risk Manag., 17(11), 111-118.

Lin, H., Cheng, W., Chen, L., Ho, H., Lin, S., \& Hsieh, C. (2021). Honokiol/MagnololLoaded Self-Assembling Lecithin-Based Mixed Polymeric Micelles (lbMPMs) for Improving Solubility to Enhance Oral Bioavailability. Int J Nanomedicine., $16(1), 651-665$.

Liu, J., Yin, Y., Yang, L., Lu, B., Yang, Z., Wang, W., \& Li, R. (2021). Nucleus-Targeted Photosensitizer Nanoparticles for Photothermal and Photodynamic Therapy of Breast Carcinoma. Int J Nanomedicine., 16(1), 1473-1485.

Liu, W., Du, B., Tan, S., Wang, Q., Li, Y., \& Zhou, L. (2020). ertical Guided Bone Regeneration in the Rabbit Calvarium Using Porous Nanohydroxyapatite Block Grafts Coated with rhVEGF165 and Cortical Perforation. Int J Nanomedicine, 10059-10073.

Liu, Z., Zhu, X., \& Tang, R. (2020). Electrospun Scaffold with Sustained Antibacterial and Tissue-Matched Mechanical Properties for Potential Application as Functional Mesh. Int J Nanomedicine., 15(1), 4991-5004.

Loutfy, S., Elberry, M., Farroh, K., Mohamed, H., Mohamed, A., Mohamed, E., . . . Mousa, S. (2021). Antiviral Activity of Chitosan Nanoparticles Encapsulating Curcumin Against Hepatitis C Virus Genotype 4a in Human Hepatoma Cell Lines [Corrigendum]. Int J Nanomedicine, 16(1), 1927-1928. 
Luo, L., Li, J., Wu, Y., Qiao, J., \& Fang, H. (2021). Adiponectin, but Not TGF- $\beta 1$, CTGF, IL-6 or TNF- $\alpha$, May Be a Potential Anti-Inflammation and Anti-Fibrosis Factor in Keloid. J Inflamm Res, 14(1), 907-916.

Ma, Y., Li, G., Yu, M., Cao, K., Li, Q., Sun, X., . . Wang, X. (2021). Anti-Lung Cancer Targets of Radix Paeoniae Rubra and Biological Molecular Mechanism: Network Pharmacological Analyses and Experimental Validation. Onco Targets Ther., 14(1), 1925-1936.

Martinez, J. (2009). Regeneración tisular guiada: técnicas periodontales . Revista Nacional de Odontología México .

Mazaheri, M., Eslahi, N., Ordikhaln, F., Tamjid, E., \& Simchi, A. (2015). Nanomedicine applications in orthopedic medicine: state of the art. Int J Nanomedicine , 60396055.

McCravy, M., Ingram, J., \& Que, L. (2021). Dysregulated Metabolism in the Pathophysiology of Non-Allergic Obese Asthma. J Asthma Allergy, 14(1), 179181.

Moin, A., Gangadharappa, H., Adnan, M., Rizvi, S., Ashraf, S., Patel, M., . . A Allam, A. (2021). Modulation of Drug Release from Natural Polymer Matrices by Response Surface Methodology: in vitro and in vivo Evaluation. Drug Des Devel Ther., 14(1), 5325-5336.

Morales, D. (2014). Tissue engineering as a pillar of regenerative medicine in dentistry. Rev Cubana Estomatología, 288-304.

MSP. (2011). Ley Orgánica de Transplante de örganos, Tejidos y Células (Vol. 1). Quito , Ecuador .

Orive, G., Hernández, R., Garcón, A., Igartúa, M., \& Pedráz, J. (2003). Ingeniería Tisular: Retos y Realidades. Medellín: Vitae.

Rabiee, N., Ahmadi, S., Arab, Z., Bagherzadeh, M., Safarkhani, M., Nasseri, B., . . . Tayebi, L. (2020). Aptamer Hybrid Nanocomplexes as Targeting Components for Antibiotic/Gene Delivery Systems and Diagnostics: A Review. Int $J$ Nanomedicine., 15(1), 4237-4256.

Rockwood, D., Prenda, R., \& Kaplan, D. (2011). Materials fabrication from Bombyx mori silk fibroin. Tufts University, 11-14.

Serrato, D., Nieto, R., \& Aguilera, A. (2015). Ingeniería de tejitos. Una nueva disciplina en medicina regenerativa. Investigación y Ciencia, 60-69.

Sha, X., Dai, Y., Song, X., Liu, S., Zhang, S., \& Li, J. (2021). The Opportunities and Challenges of Silica Nanomaterial for Atherosclerosis. Int J Nanomedicine, 16(1), 701-714. 
Shen, Q., Yang, H., Peng, C., Zhu, H., Mei, J., Huang, S., . . Cao, S. (2019). Capture and biological release of circulating tumor cells in pancreatic cancer based on peptide-functionalized silicon nanowire substrate. Int J Nanomedicine., 14(1), 205-214.

Talaat, W., Aryal, A., Al-Kawas, S., Samsudin, A., Kandile, N., Harding, D., . . Haider, M. (2020). Nanoscale Thermosensitive Hydrogel Scaffolds Promote the Chondrogenic Differentiation of Dental Pulp Stem and Progenitor Cells: A Minimally Invasive Approach for Cartilage Regeneration. Int J Nanomedicine., 15(1), 7775-7789.

Tao, J., Chow, S., \& Zheng, Y. (2019). Application of flash nanoprecipitation to fabricate poorly water-soluble drug nanoparticles. Acta Pharm Sin B, 9(1), 4-18.

TaŞli, P., YalÇin-Ülker, G., Cumbul, A., Uslu, Ü., Yilmaz, Ş., Bozkurt, B., \& Şahİn, F. (2020). In vitro tooth-shaped scaffold construction by mimicking late bell stage. Turk J Biol., 44(5), 315-326.

Tortorella, S., Vetri-Buratti, V., Maturi, M., Sambri, L., Comes-Franchini, M., \& Locatelli, E. (2020). Surface-Modified Nanocellulose for Application in Biomedical Engineering and Nanomedicine: A Review. Int J Nanomedicine, 9909-9937.

Vidu, R., Rahman, M., Mahmoudi, M., Enachescu, M., Poteca, T., \& Opris, I. (2014). Nanostructures: a platform for brain repair and augmentation. Front Syst Neurosci, 8(91).

Wang, P., Yan, Y., Zhang, Y., Gao, T., Ji, H., Guo, S., . . Dong, Y. (2021). An Improved Synthesis of Water-Soluble Dual Fluorescence Emission Carbon Dots from Holly Leaves for Accurate Detection of Mercury Ions in Living Cells. Int $J$ Nanomedicine., 16(1), 2045-2058.

Wang, Z., Hui, A., Zhao, H., Ye, X., Zhang, C., Wang, A., \& Zhang, C. (2020). A Novel 3D-bioprinted Porous Nano Attapulgite Scaffolds with Good Performance for Bone Regeneration. Int J Nanomedicine., 15(1), 6945-6960.

Weska, R., Vieira, C., \& Nogueira, G. (2009). Effect of Freezing Methods on the Properties of Lyophilized Porous Silk Fibroin Membranes. Materials Research, $2-4$.

Wong, J., Chan, K., \& Chrzanowski. (2014). Silk for pharmaceutical and cosmeceutical. En U. o. Australia. Sidney: Woodhead .

Xie, X., Shi, X., Wang, S., Cao, L., Yang, C., \& Ma, Z. (2020). Effect of AttapulgiteDoped Electrospun Fibrous PLGA Scaffold on Pro-Osteogenesis and Barrier Function in the Application of Guided Bone Regeneration. Int J Nanomedicine., 15(1), 6761-6777. 
Xuan, C., Li, H., Tian, Q., Guo, J., He, G., Lun, L., \& Wang, Q. (2021). Quantitative Assessment of Serum Amino Acids and Association with Early-Onset Coronary Artery Disease. Clin Interv Aging., 16(1), 465-474.

Yang, L. L., Wu, Y. D., Yin, J. M., Chen, H., Dong, Y., Zhang, Q., \& Zhao, L. (2020). Preparation of PU/Fibrin Vascular Scaffold with Good Biomechanical Properties and Evaluation of Its Performance in vitro and in vivo. Int J Nanomedicine., 15, 8697-8715.

Yao.C, Li, X., \& Song, T. (2009). Biodegradable nanofibrous membrane of zein/silk fibroin by electrospinning. SCI, 2,3.

Zare, H., Ahmadi, S., Ghasemi, A., Ghanbari, M., Rabiee, N., Bagherzadeh, M., . . . Mostafavi, E. (2021). Carbon Nanotubes: Smart Drug/Gene Delivery Carriers. Int J Nanomedicine., 16(1), 1681-1706.

Zeng, D., Zhang, X., Wang, X., Cao, L., Zheng, A., Du, J., . . . Jiang, X. (2017). Fabrication of large-pore mesoporous Ca-Si-based bioceramics for bone regeneration. Int J Nanomedicine., 12(1), 8277-8287.

Zheng, C., Yang, Z., Chen, S. Z., Rao, Z., Zhao, C., Quan, D., . . . Shen, J. (2021). Nanofibrous nerve guidance conduits decorated with decellularized matrix hydrogel facilitate peripheral nerve injury repair. Theranostics, 11(6), 2971-2931.

Zhou, J., Xiong, Z., Liu, M., Yang, L., Yao, S., Chen, K., . . . Guo, X. (2020). Creation of Bony Microenvironment with Extracellular Matrix Doped-Bioactive Ceramics to Enhance Osteoblast Behavior and Delivery of Aspartic Acid-Modified BMP-2 Peptides. Int J Nanomedicine., 15(1), 8465-8478.

Zhou, Y., Yang, Q., Wang, F., Zhou, Z., Xu, J., Cheng, S., \& Cheng, Y. (2021). SelfAssembled DNA Nanostructure as a Carrier for Targeted siRNA Delivery in Glioma Cells. Int J Nanomedicine, 16(1), 1805-18017.

\section{Ciencia}




\section{PARA CITAR EL ARTÍCULO INDEXADO.}

Guerra Villacis, J. S., Rachid, S., Narváez Muño, C. P., \& Torres Arias, M. (2021). Biopolímeros: Aplicaciones de andamios en medicina regenerativa. Anatomía Digital, 4(3), 6-33. https://doi.org/10.33262/anatomiadigital.v4i3.1754

\section{¿Ciencia}

El artículo que se publica es de exclusiva responsabilidad de los autores y no necesariamente reflejan el pensamiento de la Revista Anatomía Digital.

El artículo queda en propiedad de la revista y, por tanto, su publicación parcial y/o total en otro medio tiene que ser autorizado por el director de la Revista Anatomía Digital.
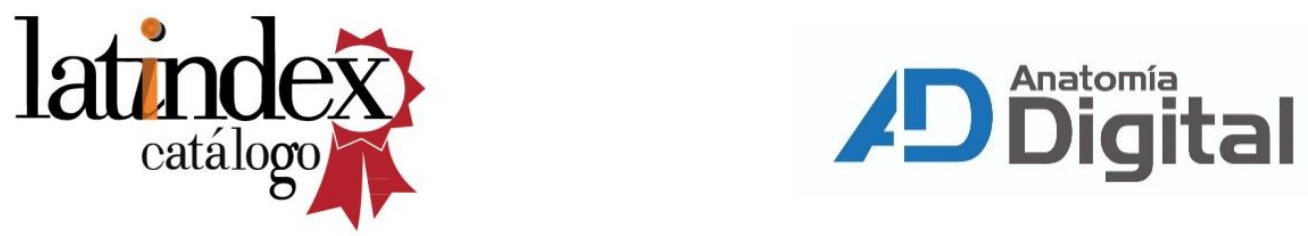